Research Article

\title{
Extraction and Determination of Chemical Structure from Flower Dicholoromethane Extract of Catharanthus roseus
}

\section{Shahin Aziz ${ }^{a^{*}}$, Koushik Saha ${ }^{b}$, Md. Abdus Satter Miac, Md. Hemayet Hossain ${ }^{a}$}

${ }^{1}$ Chemical Research Division, BCSIR Laboratories Dhaka, Bangladesh Council of Scientific and Industrial Research, Dhamondi, Dhaka-1205, Bangladesh.

${ }^{\text {b} D e p a r t m e n t ~ o f ~ C h e m i s t r y, ~ J a h a n g i r n a g a r ~ U n i v e r s i t y, ~ S a v a r, ~ D h a k a-1342, ~ B a n g l a d e s h . ~}$

'IFST, BCSIR, Dhaka, Bangladesh.

*Corresponding author's E-mail: shaziz2408@yahoo.com

Received: 22-03-2021; Revised: 18-05-2021; Accepted: 04-06-2021; Published on: 15-06-2021. ABSTRACT

Catharanthus roseus is considered a cooling medicine. Two compounds: $\beta$-sitosterol (1) and 3 $\beta$-Hydroxy-lup-20 (29)-en-28-oic acid or Oleanolic acid (2) have been isolated from flowers from Dicholoromethane extract of Catharanthus roseus. By different spectroscopic data analysis the structures of the compounds have been established.

Keywords: Catharanthus roseus, isolation, structure elucidation, spectroscopic methods.

QUICK RESPONSE CODE $\rightarrow$

DOI:

10.47583/ijpsrr.2021.v68i02.007

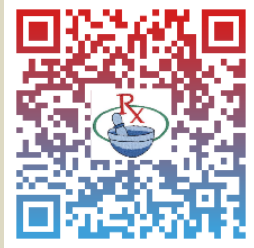

DOI link: http://dx.doi.org/10.47583/ijpsrr.2021.v68i02.007

\section{INTRODUCTION}

$\mathrm{P}$

lants are sources of drug which have great contribution for curing human life ${ }^{1}$. During the early years of human existence, many plants materials by instinct, intuition of trial and error were used to combat different aliments ${ }^{2}$.

Catharanthus roseus, Bengali- Nayantara, SynonymsVincarosea; Family-Apocyanaceae, an important medicinal plant. It is a potential source for anti-leukemic alkaloids. It has many alkaloids which are having anticancer activities ${ }^{3}$. This plant is considered as a cooling medicine. This plant is used for the treatment of diabetes, fever, malaria, throat infection and chest complaints. It is also used for the regulation of menstrual cycles, and as a euphoriant ${ }^{4}$. some popular indole alkaloids are present in all plant parts. The physically important and antineoplastic alkaloids namely Vincristine and Vinblastine are mainly present in the leaves whereas antihypertensive alkaloids such as ajmalicine, serpentine and reserpine are reported to be present in the roots ${ }^{5}$ Vincristine and Vinblastine alkaloids are used in the treatment of various types of lymphoma and leukemia ${ }^{6-7}$. These Catharanthus alkaloids are also used for the treatment of both malignant and nonmalignant diseases and in platelet and platelet associated disorder. From Previous phytochemical investigations some secondary metabolites like Kaemfero ${ }^{8}$, Kaempferoltrisaccarides ${ }^{9}$, Quercetin $^{10}$, Quercetintrisaccarides ${ }^{8}$, Syringetin glycosides $^{11}$, Malvidin ${ }^{10}$, Malvidin 3-0-glucosides ${ }^{12}$, Malvidin 3-0-(6-0-p-coumaroyl) ${ }^{12}$, Petunidin $^{10}$, Petunidin 3-0-glucosides ${ }^{12}$, Petunidin 3-0-(6-0-p-coumaroyl) 12, Hirsutidin ${ }^{10}$, Hirsutidin 3-0-glucosides ${ }^{12}$, Hirsutidin 3-0-(60 -p-coumaroyl) ${ }^{12}$, Rutin ${ }^{13}$ were found. The alkaloids found from several part of the plants are antineo plastic medicines and the monoindole alkaloids ajmalicin and serpentine are antihypertension drugs ${ }^{14-20}$. Our recent study on dicholoromethane (DCM) part of flower and leaf of this plant has led to the isolation of $\beta$-sitosterol (1) and $3 \beta$-Hydroxy-lup-20 (29)-en-28-oic acid or Oleanolic acid (2).

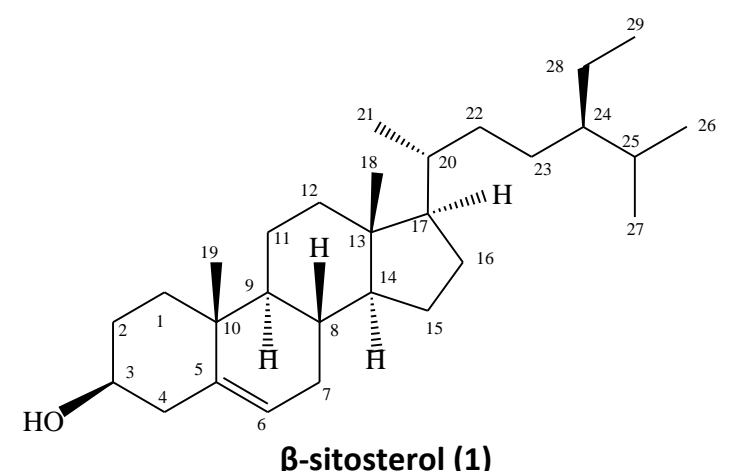

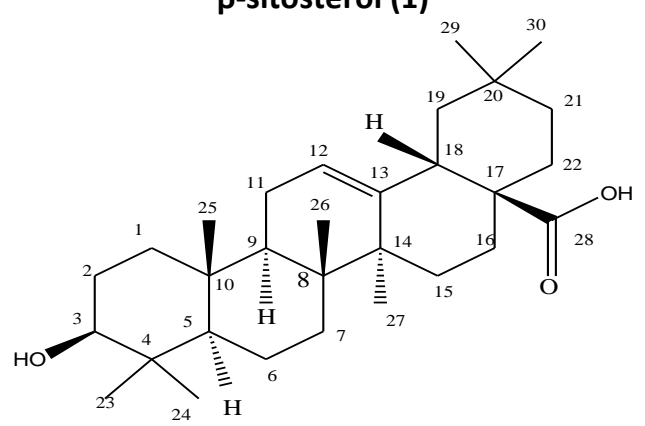

3ß-Hydroxy-lup-20 (29)-en-28-oic acid or Oleanolic acid (2)

Figure 1: Structures of the isolated compounds with numbering. 


\section{MATERIALS AND METHODS}

Melting points were determined by thin disc method on a Fisher-John's electro thermal melting point apparatus. UV spectra were recorded in methanol on a Shimadzu UVVisible spectrophotometer. IR spectra were recorded on a Shimadzu FT-IR spectrometer as thin film orKBr disc. NMR spectra were recorded in $\mathrm{CDCl}_{3}$ using Bruker WH $400 \mathrm{MHz}$ NMR spectrometer. Mass spectra of the compounds were measured on Finnigan Mat SSQ 710 spectrometer with ionization induced by electron impact at $70 \mathrm{eV}$. Separation by column chromatography was carried out using silica gel 40 (70-230 mesh, E. Merck). Thin layer chromatography was carried out on TLC plastic sheets pre-coated with silica gel $60 \mathrm{~F}_{254}$ (E. Merck).

\section{Collection of plant material}

Fully matured fresh flowers of this plant were collected from the gardens of Chemistry Department of Dhaka university, Bangladesh in June 2013 and identified by the taxonomist of Bangladesh national Herbarium, Dhaka, where a voucher specimen (No. = 39512) has been deposited. The flowers of C.roseus were air dried. These dried samples of flowers were powdered using 20 mesh screen in Willey mill and then used for subsequent analysis.

\section{Extraction of the flower parts of $C$. roseus}

Dried, grinned and screened flower powder (200g) was extracted successively with different solvent at room temperature. At first it was extracted with $n$-hexane for 5 days and the extract was dried to get a gummy mass $(2.50$ g) using rotary evaporator. Then the residual part of the flower was extracted with dichloromethane for 5 days and the extract was dried to gummy mass $(5.80 \mathrm{~g})$.

\section{Isolation of compounds from crude extracts}

DCM extract ( $1.8 \mathrm{~g}$ ) was dissolved in minimum amount of solvent and adsorbed with silica-gel. TLC analysis of the DCM extract showed several spots under UV lamp followed by the development using spray reagent on TLC plate in different solvent systems. A column was packed with same grade silica gel in $100 \% \mathrm{n}$-hexane and the adsorbed extract was put on the top of the column. The column was eluted with $100 \%$ n-hexane, hexane-ethyl acetate, ethyl acetate, ethyl acetate-methanol and methanol in gradient manner. Total 180 test tubes were collected with $20 \mathrm{ml}$ each and the collections were divided into eight fractions according to their TLC behaviors. Fr.2 (collection no. 31-56) and Fr. 4 (collection no. 72-78) of column chromatographic separation of DCM extract of flowers were selected for further purification due to their good resolution on TLC plate. The fraction 2 (collection no. 31-56) was concentrated by evaporation of solvent using rotary evaporator and found light colored crystals. It was then washed with little amount of $n$-hexane and DCM to remove coloring materials to get compound (1) $(8.4 \mathrm{mg})$ as colorless needle shaped crystals in pure form.
White colored powder was precipitated out from the solution of the column fraction 4 (collection no. 72-78) of DCM extract which was then separated and washed with little $\mathrm{n}$-hexane and DCM, respectively. Finally the compound compound (2) $(8.8 \mathrm{mg})$ was purified by crystallization from methanol to get as white powder as TLC pure.

\section{Spectroscopic data of the isolated compounds}

\section{$\beta$-sitosterol (1)}

Colorless needle shaped crystals; mp $135-137^{\circ} \mathrm{C}$; IR (neat) u 3410 (O-H), 2956, 2862, 1673 (C=C), 1463, 1375, 1051 (CO) $\mathrm{cm}^{-1}{ }^{1}{ }^{1} \mathrm{H}$ NMR $\left(\mathrm{CDCl}_{3}\right) \delta 5.33(1 \mathrm{H}, \mathrm{m}, \mathrm{H}-6), 3.51(1 \mathrm{H}, \mathrm{m}$, $\mathrm{H}-3), 2.18-2.32(2 \mathrm{H}, \mathrm{m}), 1.92-2.03(2 \mathrm{H}, \mathrm{m}), 1.78-1.87(2 \mathrm{H}$, $m), 1.42-1.68(12 \mathrm{H}, \mathrm{m}), 1.22-1.38(8 \mathrm{H}, \mathrm{m}), 1.05-1.20(4 \mathrm{H}$, m), $0.99(3 \mathrm{H}, \mathrm{s}, \mathrm{H}-19), 0.91(3 \mathrm{H}, \mathrm{d}, J=6.4 \mathrm{~Hz}, \mathrm{H}-21), 0.83(3 \mathrm{H}$, $\mathrm{t}, J=7.2 \mathrm{~Hz}, \mathrm{H}-29), 0.82(3 \mathrm{H}, \mathrm{d}, J=7.6 \mathrm{~Hz}, \mathrm{H}-26$ or H-27), 0.80 $\left(3 \mathrm{H}, \mathrm{d}, \mathrm{J}=7.2 \mathrm{~Hz}, \mathrm{H}-26\right.$ or H-27), $0.66(3 \mathrm{H}, \mathrm{s}, \mathrm{H}-18) ;{ }^{13} \mathrm{C}$ NMR $\left(\mathrm{CDCl}_{3}\right) \delta 140.4$ (C-5), 121.3 (C-6), 71.4 (C-3), 56.4, 55.7, $49.8,45.5,41.9(2 \mathrm{C}), 39.4,36.9,36.1,35.8,33.6,31.5(2 \mathrm{C})$, $31.3,28.8,27.9,25.7,23.9,22.7,20.7,19.4,19.0,18.6$, 18.4, 11.6, 11.5; MS m/z $414\left(\mathrm{M}^{+}\right), 399,396,385,329,301$, $273,255,231,213,159,145,138,121,55,43$ (base peak).

\section{$3 \beta$-Hydroxy-lup-20 (29)-en-28-oic acid or Oleanolic acid} (2)

White powder ; mp 280-282 C; IR (neat) u 3410 ( br O-H), 2924, 2856, 1685 (C=O ), 1456,1375, 1238, 1188 (C-O) cm ${ }^{1 ;}{ }^{1} \mathrm{H}$ NMR $\left(\mathrm{CDCl}_{3}\right) \delta 5.24(1 \mathrm{H}, \mathrm{m}), 3.21(1 \mathrm{H}, \mathrm{m}), 2.32(3 \mathrm{H}$, $\mathrm{m}), 1.84-2.09(2 \mathrm{H}, \mathrm{m}), 1.45-1.72(13 \mathrm{H}, \mathrm{m}), 1.40-1.17(24 \mathrm{H}$, $\mathrm{m}), 1.12(3 \mathrm{H}, \mathrm{s}), 1.07(3 \mathrm{H}, \mathrm{s}), 0.97(3 \mathrm{H}, \mathrm{s}), 0.83-0.94(12 \mathrm{H}$, $\mathrm{m}), 0.76(6 \mathrm{H}, \mathrm{m}) ;{ }^{13} \mathrm{CNMR}\left(\mathrm{CDCl}_{3}\right) \delta 182.41(\mathrm{C}=0), 125.8$, 79.1, 55.2, 52.6, 47.9, 47.5, 42.0, 39.5, 39.0, 38.7, 38.6, $37.0,36.7,33.7,32.9,31.8,30.6,29.6,29.1,28.1,27.2$, 24.6, 24.1, 23.6, 23.3, 22.6, 21.2, 18.3, 17.0, 15.6, 14.1.

\section{RESULTS AND DISCUSSION}

From DCM flower extract the compound (1) $(8.4 \mathrm{mg}$ ) was found as colorless needle shaped crystals and was soluble in chloroform. Melting point of the compound was found as $135-137^{\circ} \mathrm{C}$. It showed single spot on TLC plate with $R_{f}$ value 0.26 in $20 \%$ Chloroform in pet ether.The mass spectrum of the compound showed a molecular ion peak at $\mathrm{m} / \mathrm{z} 414$ which is corresponding to the molecular formula $\mathrm{C}_{29} \mathrm{H}_{50} \mathrm{O}$. The IR spectrum of the compound showed a broad absorption band at $3410 \mathrm{~cm}^{-1}$ indicating the presence of hydroxyl group in the molecule. The compound also showed absorption bands at 2956 and $2862 \mathrm{~cm}^{-1}$ due to saturated $\mathrm{C}-\mathrm{H}$ stretching vibrations. The band at $1673 \mathrm{~cm}^{-1}$ due to $\mathrm{C}=\mathrm{C}$ stretching vibration, sharp bands at 1463 and $1375 \mathrm{~cm}^{-1}$ due to saturated $\mathrm{C}-\mathrm{H}$ bending vibrations and the band at $1051 \mathrm{~cm}^{-1}$ due to alcoholic $\mathrm{C}-\mathrm{O}$ stretching vibration indicated in the IR spectrum.

The ${ }^{1} \mathrm{H}$ NMR spectrum of the compound showed $3 \mathrm{H}$ singlets at $\delta 0.99 \& 0.66,3 \mathrm{H}$ doublets at $\delta 0.91,0.82, \& 0.80$ and $3 \mathrm{H}$ triplet at $\delta 0.83$. These data clearly indicated the presence of six methyl groups in the molecule. The one proton multiplet at $\delta 3.51$ indicated the presence of 
$>\mathrm{CHOH}$ group in the compound. The peak at $\delta 5.33(1 \mathrm{H}, \mathrm{m})$ confirmed the presences of one olefinic proton at C- 6 and this was further supported by the ${ }^{13} \mathrm{C}$ NMR spectral data at $\delta 140.4$ and 121.3 for two olefinic carbons (C-5 \& C-6). The C-3 attached with hydroxyl group also supported by showing peak at $\delta 71.4$ in the ${ }^{13} \mathrm{C}$ NMR spectrum. The presence of 29 carbons in the molecule of F3 was clearly indicated by twenty-seven signals in the ${ }^{13} \mathrm{C} N M R$ spectrum. The two intensified peaks at $\delta 41.9$ and 31.5 were due to two pairs of carbons. All the above data suggested that the compound is a steroidal molecule containing one hydroxyl group, one double bond and six methyl groups. Finally, the fragment ions present in the mass spectrum confirmed the structure of the compound. Based on all spectroscopic data, literature values ${ }^{21}$ and melting point of the compound, it was confirmed that the compound (1) is $\beta$-sitosterol. The structure of the compound (1) is given bellow:

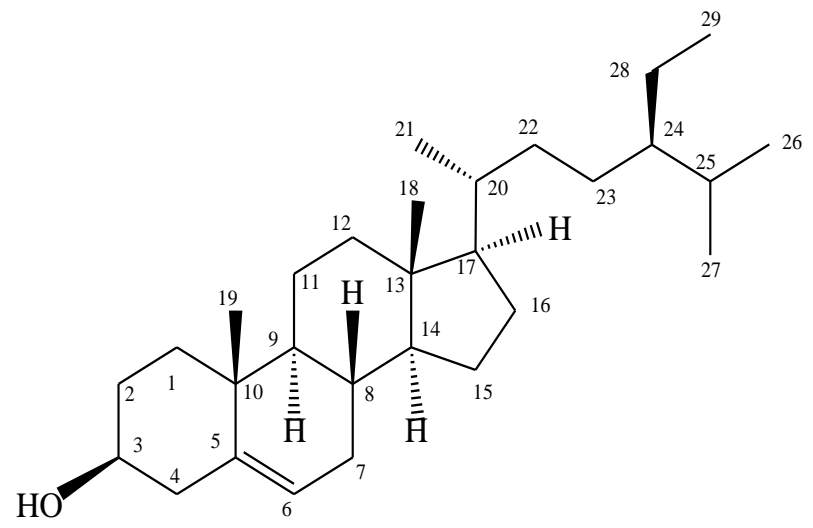

B-sitosterol (1)

The compound (2) (8.8 mg) was found as white powder and was soluble in chloroform. The absorption band at 3410 and $1685 \mathrm{~cm}^{-1}$ showed in the IR spectrum indicated the presence of $\mathrm{O}-\mathrm{H}$ and $\mathrm{C}=\mathrm{O}$ stretching vibrations, respectively. The $\mathrm{C}-\mathrm{O}$ stretching vibrations were assigned by the bands at $1238 \& 1188 \mathrm{~cm}^{-1}$ in the same spectrum.

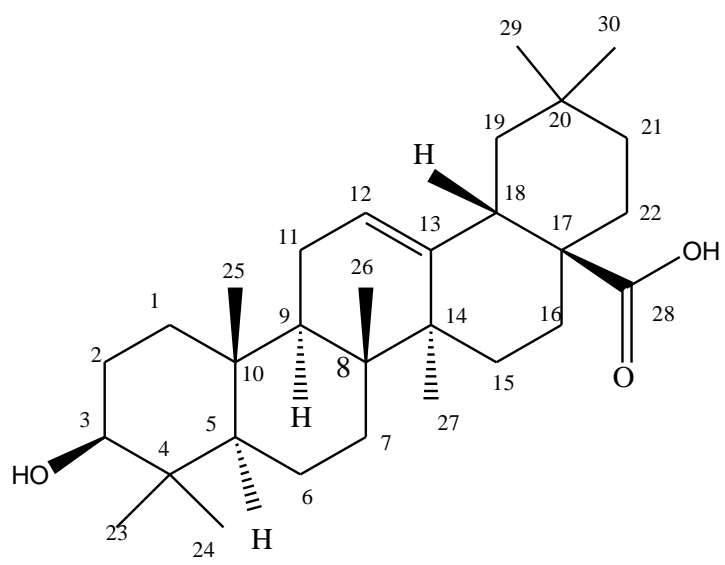

3ß-Hydroxy-lup-20 (29)-en-28-oic acid or Oleanolic acid (2)

In the ${ }^{1} \mathrm{H}$ NMR spectrum, the multiplet at $\delta 5.24$ was found due to the presence of olefinic proton in the molecule. The multiplet at $\delta 3.21$ indicated the presence of $>\mathrm{CH}-\mathrm{OH}$ group and the peaks in the region $\delta 0.76$ to 1.12 showed the presence of a number of methyl groups in the structure. The ${ }^{13} \mathrm{C}$ NMR spectrum of the compound showed the signed at $\delta 182.4$ indicated the presence of carbonyl carbon of carboxyl group. The peak at $\delta 79.1$ indicated the carbon which is attached to the hydroxyl group. The olefinic carbon indicated by the peak at $\delta 125.8^{22}$. The spectral data of the compound (2) is very much similar to that of oleanolic acid. Based on the analysis of spectral data, the compound (2) was suggested as oleanolic acid with impurity. The structure is given below:

\section{CONCLUSION}

Literature survey showed that very little phytochemical studies have been done on flower DCM extract of the plant Catharanthus roseus. The isolation and characterization of three compounds from flower part of the plant have been reported here. We believe, there is a scope to do more detailed phytochemical and biological study on this plant in future.

Acknowledgement: We are grateful to Division in charge, Chemical Research Division, BCSIR Laboratories, Dhaka and Director, BCSIR Laboratories, Dhaka, for providing necessary facilities to carry out this research work.

\section{REFERENCES}

1. Sofowora AA: Medicinal Plants and Traditional Medicine in West Africa. Second Edition, John Willey and Sons Ltd. New York. 1993:pp.289.

2. Ogundare AO, Antimicrobial Effect of Tithonia diversifolia and Jatropha gossypifolia Leaf extracts. Trends in Applied Science and Research. 2007; 2 (2): 145-150.

3. Jaleel,C.A., Gopi R. and Paneerselvam R. Alterations in non-enzymetic antioxidant components of Catharanthus roseus exposed to paclobutrazol, gibberellic acid and Pseudomonas fluorescens. Plant Omics J. 2009: 2(1):30-40.

4. Ambusta CS. The Wealth of India. Raw Materials (Revised Edition), Publication and Information Directorate, CSIR, New Delhi. 1992; 3:117.

5. Mishra P, Uniyal GC, Sharma S. and Kumar S. Pattern of diversity for morphological and alkaloid yield related traits among the periwinkle Catharanthus roseus accessions collected from in and around Indian Subcontinent. Genetic Res Crop Evol. 2001;48: 273-286.

6. Farnsworth N.R., Svoboda GH, Blomster RN., Antiviral activity of selected Catharanthus alkaloids. J.Pharm.Sci. 1968; 57: 2174-2175.

7. Gajalakshmi S, Vijayalakshmi S and Devi Rajeswari V. Pharmacological activities of Catharanthus roseus, a prospective review. Int J Pharm Bio Sci. 2013: 4(2): 431439.

8. Forsyth W.G.C, Simmonds N.W., Anthocyanidins of Lochnera rosea. Nature 1957; 180:247.

9. Nishibe S, Takenaka T, Fujikawa T., Yasukuwa K, Takido M, Morimitsu Y, Hirota A, Kawamura T, NoroY, Bioactive 
compounds from Catharnthus roseus and Vinca minor. Natural medicines (Tokyo). 1995,50:378-383.

10. Bruneton J, Pharmacognosy: phytochemistry medicinal plants, 2 edn. Intercept Ltd., hampshire, UK. 1999,pp 227231.

11. Filippini R, Caniato R, Piovan A, Cappelletti E.M., Production of anthocyanins by Catharanthus roseus. Fitoterapia. 2003, 74: 62-67.

12. Srinivasa R.A, Fazil M.A., Simultaneous estimation of quercetin and rutin in ethanolic extract of Catharanthus roseus .Linn Leaves by HPLC method, International Global Research Analysis, 2013, vol-2, Issue:7, ISSN No. 22778160.

13. Zhao J, Verpoorte R. Manipulating indole alkaloid production by Catharanthus roseus call cultures in bioreactores: from biochemical processing to metabolic engineering. Phytochemistry Reviews . 2007;6:435-457.

14. Atta-Ur-Rahman, Bashir M. ,Hafeez M, Parveen N, Fatima J. 16-Epi-19-s-vindlinine, an indole alkaloids from C.roseus. planta Med.1983; 47:246-247

15. Atta-Ur-Rahman, Fatima J. Isolation and structure of rosicine from $C$. roseus. Tetrahedron letters. 1984; 25:52.6051-6054
16. Atta-Ur-Rahman, Ali I, Bashir M. "Isolation of rhazinal from the leaves of C. roseus" .J natural Products. 1984; 47:2.389

17. Atta-Ur-Rahman, Ali I, Chudhury. Isolation and 13CNMR studies on cathovaline on alkaloid from leaves of $C$. roseus .planta Medica. 1985; 5:447-448

18. Atta-Ur-Rahman, Alam M, Ali I, Habib-ur-Rahman, Huq I, "Leurosinone: a new binary indole alkaloid from C. roseus “perkin-transaction-I No8. 1988; 2175-2178

19. Auriola S, Naaranlahti T, Kostianen R, LapinjakiSp. "Identification of indole alkaloid from $C$. roseus with liquid chromatography/mass spectrophotometry using collision -induced dissociation with thermospary ion repeller" Biomed Environ mass Spectrum. 1990:400-404. July, 19,7.

20. Nikita V, Tayade DT, Rahimullah SU. Studies in the proximate analysis of leaves of Murrayakoenigi L. from Amravati belongs to Maharashtra state. Int. J. of Natural Products Research. 2012; 1(3): 40-41.

21. Rajput AP, "Isolation of Stigmastrol and $\beta$-Sitosterol from chloroform extract of leaves of Corchorus fascicularis Lam" Int. J. of Biological Chemistry. 2012; 6(4): 130-135.

22. Enamul H, Hussain US, Akim UM, Hafizur R, Mydul Islam AKM, Sabir Hossin M, "Triterpenoids from the stem bark of Avicennia Officinalis". Dhaka Univ. J. Pharm Sci. 2006; 5 (12): 53-57.

Source of Support: The author(s) received no financial support for the research, authorship, and/or publication of this article.

Conflict of Interest: The author(s) declared no potential conflicts of interest with respect to the research, authorship, and/or publication of this article.

For any question relates to this article, please reach us at: editor@globalresearchonline.net New manuscripts for publication can be submitted at: submit@globalresearchonline.net and submit_ijpsrr@rediffmail.com 